\title{
Coupled Vibration of Unshrouded Centrifugal Compressor Impellers. Part I: Experimental Investigation*
}

\author{
HEINRICH HASEMANN, DIRK HAGELSTEIN ${ }^{\dagger}$ and MANFRED RAUTENBERG \\ Institute of Turbomachinery, University of Hannover, Appelstr. 9, D-30167 Hannover, Germany
}

(Received 12 May 1998; In final form 21 July 1998)

\begin{abstract}
The increased use of small gas turbines and turbochargers in different technical fields has led to the development of highly-loaded centrifugal compressors with extremely thin blades. Due to the high rotational speed and the corresponding centrifugal load, the shape of the impeller hub must also be optimized. This has led to a reduction of the thickness of the impeller disc in the outlet region. The thin parts of the impeller are very sensitive and may be damaged by the excitation of dangerous blade vibrations.

Experimental investigations by means of holographic interferometry and telemetry were carried out for two different impeller types; one with radial-ending blades and the other with backswept blades. The results presented in Part $I$ of the paper are able to explain the dominance of coupling effects between the blades and the disc in the middle and higher frequency range of the two tested impellers. Especially excitations caused by downstream sources such as vaned diffusers can endanger the blades and the impeller.

The finite element (FE) code computations presented in Part II of the paper to investigate the coupled vibration behavior of the whole impeller were found to be in close agreement with the experimental results.
\end{abstract}

Keywords: Centrifugal compressor, Holographic interferometry, Blade vibrations, Coupled vibrations

\section{INTRODUCTION}

Compressors find wide application in many branches of technology. They serve for compressing and transporting diverse gases and gas mixtures and convert mechanical energy into pressure energy.

In the further development of centrifugal compressor impellers to achieve ever-increasing power concentrations, considerable effort has been directed towards the construction of small compact units with high pressure stage ratios and large mass flow rates. As this objective may only be realized with increased peripheral speed, it is not only necessary to employ improved and also more expensive impeller materials but also to reduce the blade thicknesses as well as the wall thicknesses of

\footnotetext{
* This paper was originally presented at ISROMAC-7.

${ }^{\dagger}$ Corresponding author. Tel.: (0511)762-2737. Fax: (0511)762-2768.
} 
the impeller disc in order to ensure that the loads due to centrifugal forces remain within permissible limits. At the same time, however, there is an increasing risk of dangerous excitation vibrations of these very thin and flexible blades. As confirmed by operational practice, the failure of highly-loaded impellers is in many cases due to blade breakage resulting from dynamic overloading of the blade material. This leads to plant shutdown and costly outage times. The blade vibrations of these impellers during operation are thus gaining increasing importance with regard to design strength criteria.

Generally speaking, the lower mode shapes and especially the fundamental mode of vibration are considered to be the most dangerous. A resonant excitation in this range should also be avoided at all costs! The excitation of higher frequency modes, however, also poses a considerable risk potential. Experimental investigations by Haupt and Rautenberg (1982a) have shown, for example, that vaned diffusers downstream of the impeller give rise to upstream excited vibrations of the whole impeller in the higher frequency range, representing a vibration state which is far more dangerous than most other causes of excitation. Excitation of the relatively flexible outer region of the impeller disc thereby results in excitation of the blades at one of their higher natural frequencies, leading to vibrations with significant amplitudes. This results in material stress peaks in the impeller inlet region approaching the limits of the maximum permissible load.

Experimental investigations by Haupt and coworkers (1982b,c; 1985) have shown that in the case of highly-loaded centrifugal compressor impellers with small blade thicknesses and thin flexible impeller discs in the outlet region, coupled vibration behavior occurs which cannot be fully described in terms of its complexity and danger risk from a mere consideration of individual blades.

The aim of the present investigations was therefore to model the complex coupled vibration behavior of the investigated impellers using the finite element method and to verify the computational results on the basis of experimental measurements obtained by means of holographic interferometry. Further details of the finite element computations are given in Part II of the paper.

\section{INVESTIGATED IMPELLERS}

Two centrifugal compressor impellers were investigated, namely, a $90^{\circ}$-impeller with radial-ending blades and a $60^{\circ}$-impeller with backswept blades. At the meridional section, both impellers have the same profile. This means that the hub profile as well as the casing profile are identical for both impellers. The external diameter of the impellers is $400 \mathrm{~mm}$ with an outlet width of $26.1 \mathrm{~mm}$. The inlet diameter is $280 \mathrm{~mm}$ while the hub diameter is $90 \mathrm{~mm}$. The impeller axis extends over a distance of $130 \mathrm{~mm}$.

\section{The $90^{\circ}$-Impeller}

The investigated impeller with radial-ending blades is shown in Fig. 1. The impeller outlet angle is $90^{\circ}$, and of the 28 blades, every second blade is cut back to reduce blockage at the inlet. The skeleton area of the blades is generated by radial rays oriented at right angles to the axis of rotation. The variation of the blade thickness from root to tip was specified by considering the static loading due to centrifugal forces as well as low aerodynamic blockage.

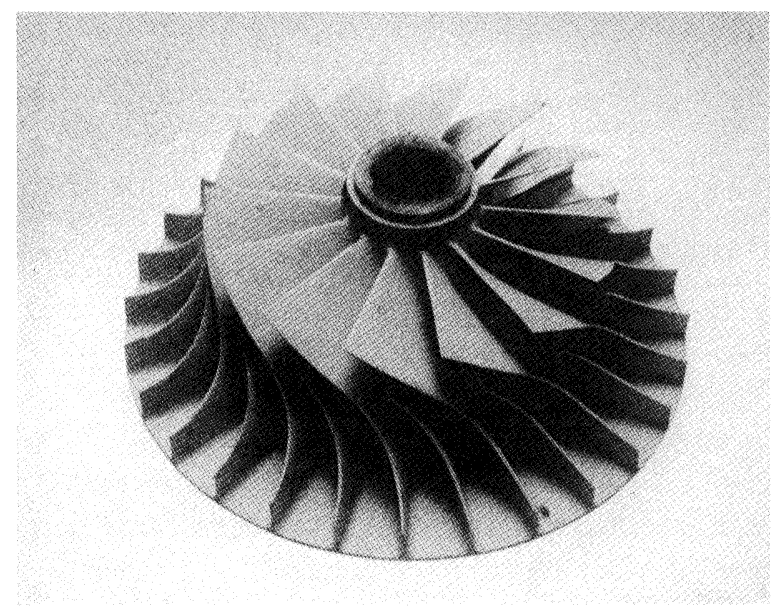

FIGURE 1 The $90^{\circ}$-centrifugal compressor impeller with 28 blades. 
The $90^{\circ}$-impeller was manufactured from a model by the profile milling method. Great care was necessary in milling the leading edge of the blade in order to avoid errors due to bending of the very thin blades as a result of milling cutting forces.

\section{The $60^{\circ}$-Impeller}

The $60^{\circ}$-impeller shown in Fig. 2 has backswept blades, i.e. the outlet angle is inclined at $60^{\circ}$ relative to the negative circumferential direction. The aerodynamic advantages of impellers with backswept blades are reflected in improved efficiency and an expansion of the performance map compared with radial-ending blades. As arched blades are no longer able to lie on radial rays at the outlet, as in the case of a $90^{\circ}$-impeller, bending stresses may be expected in this case due to centrifugal forces, thus imposing a limit on operating speeds.

This impeller has 20 blades, of which every second blade is also cut back at the inlet in order to ensure low blockage. The high static loading experienced by backswept blades due to the bending stresses induced by centrifugal forces necessitates an adaptation of the blade thickness variation from root to tip, especially in the outlet

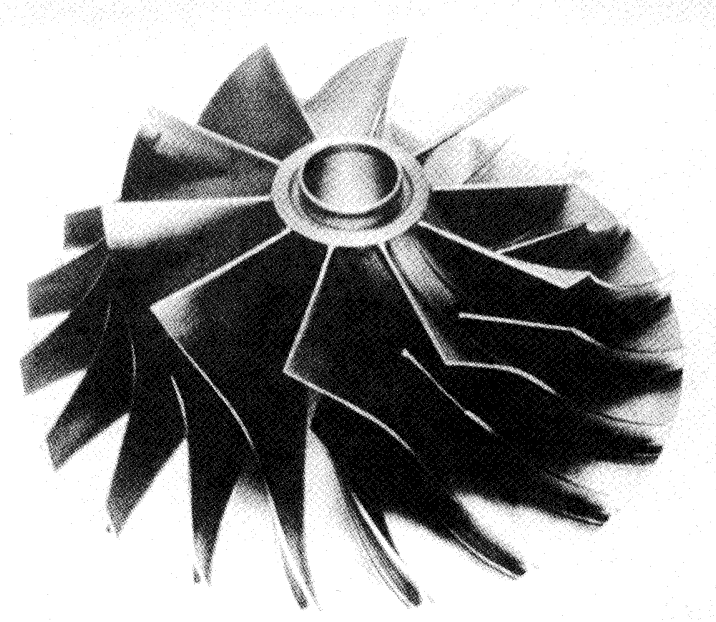

FIGURE 2 The $60^{\circ}$-centrifugal compressor impeller with 20 blades. region. Compared with the thickness variation of the $90^{\circ}$-blade, this blade is only slightly thicker.

In contrast to the impeller with radial-ending blades, the $60^{\circ}$-impeller was manufactured on a 5-axis controlled CNC milling machine by the flank milling method. The use of this method was made possible by the mathematical configuration of the blade surfaces as ruled surfaces. In this type of design the pressure and suction sides of the blades are generated from ruled lines, the end points of which are traced along the spatial curves of the hub profile and outer profile in compliance with aerodynamic specifications. The ruled surfaces thus generated by the migration of the ruled lines may be milled with the aid of 5-axis CNC technology. Although the geometry of the milling head gives rise to unavoidable errors due to the hyperbolic undercut, these may be minimized by applying a correction to the milling cutter guide (Hasemann et al., 1995).

\section{THE TELEMETRY SYSTEM}

In order to detect the blade vibration signals during operation, it was essential to deploy vibration sensors in the proximity of the rotating impeller and to transmit the signals in a suitable manner. According to Haupt (1984), conventional measuring techniques cannot be applied under the restrictive framework conditions of this type of investigation. It was therefore decided to employ a telemetry system with 8 transmission channels. Full details of the installation are reported by Haupt et al. (1984). The system operates over a frequency range up to $f=10,000 \mathrm{~Hz}$ and permits the contactless transmission of 8 instationary vibration signals from the rotating impeller, as illustrated by the investigations of Haupt and coworkers (1978; 1982).

The latter experimental investigations also demonstrate that a satisfactory determination of the complex vibration behavior of these impellers is only possible by employing a multi-channel system with simultaneous measurements of several 
vibration signals at different points on the structure. Semiconductor strain gages, which are capable of detecting local strains with high accuracy, were therefore applied to different blades and at different positions on these blades. As each mode shape is marked by characteristic and locally restricted regions with large strains, whereas other regions are virtually strain-free, and also due to coupled vibration effects resulting from mutual interactions between the blades, the points of application of the strain gages were carefully selected to achieve the largest possible detection coverage.

Figure 3 shows a longitudinal section of the impeller shaft, indicating the installations for recording and transmitting the blade vibration signals. The strains are recorded by the strain gages applied to the blades and are transmitted via the telemetry transmitter with its co-rotating antenna to the stationary receiver. Power is supplied inductively via a stationary primary coil and a rotating secondary coil. The secondary coil also serves as a transmitting antenna whereas the primary coil serves as a receiving antenna for the recording unit, which operates as a frequency multiplex system.

\section{HOLOGRAPHIC INTERFEROMETRY}

In order to determine its natural vibration behavior the impeller was investigated at rest with the aid of holographic interferometry. By means of holographic interferometry it is possible to determine the mode shapes of a vibrating body. In contrast to the strain gage technique, this method provides information over the entire surface of the body under investigation, from which the amplitude distribution may be determined. This is especially advantageous in the case of the complex geometrical structures under investigation, as it is possible to identify a mode shape relatively quickly.

Among others, the time-average technique was adopted in the holographic investigations. Figure 4 shows the experimental set-up for the optical study of the impeller. The coherent monochromatic light

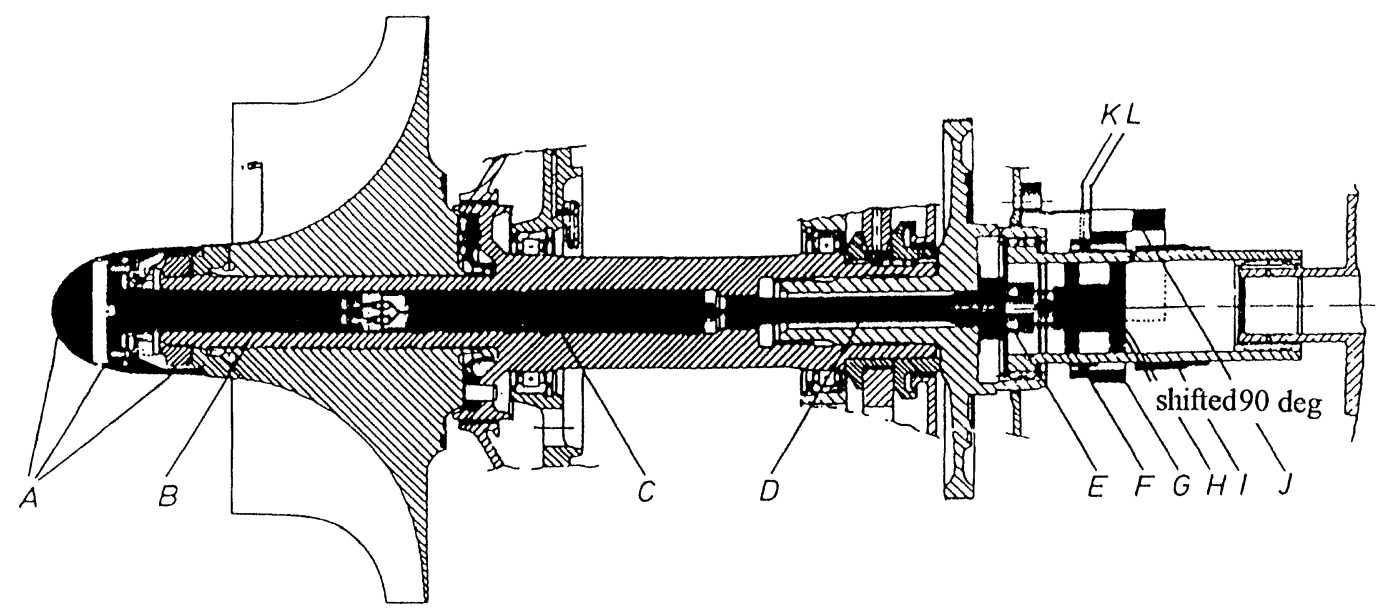
A: hub nose
B: 8-channel telemetry transmitter
C: cable carrier
D: tension screw

E: adapter with plug connection

I: trigger unit

F: secondary coil

G: primary coil

J: coil holder

H: inductive power supply switch

K: receiver antenna

L: inductive power supply

FIGURE 3 Impeller shaft with integrated telemetry transmitter for transmitting the blade vibration signals. 
from the argon laser illuminates the vibrating compressor impeller excited by a shaker via the mirrors Sp1 and Sp2 as well as the beam splitter ST, the divergence optics $\mathrm{AO} 2$ and the mirror Sp3. In the beam splitter ST, part of the coherent laser light is reflected out as a so-called reference beam. The reference beam $\mathrm{R}$ arrives at the free-standing hologram plate $\mathrm{H}$ as a plane wave without phase shift via the divergence optics AO1 and the mirror Sp4. The object beam is also reflected back to the hologram plate $\mathrm{H}$ from the compressor impeller. Interference occurs in the fine-grained photographic layer of the hologram plate between the plane, non-deformed wave front $\mathrm{A}$ of the reference wave and the diffuse, reflected, deformed wave front $\mathrm{D}$ from the vibrating impeller. This interference in the fine-grained layer of the hologram plate leads to zones of maximum illumination and mutual extinction.

The time-average method is very suitable for the investigations carried out in the present study as the extreme positions of the vibrating structure are stored in the hologram whereas the intermediate positions are not registered due to the short dwell times intrinsic to the sinusoidal vibration. When the maximum vibration amplitudes lie in the range of $0.2-15 \mu \mathrm{m}$, interference occurs once again between the two wave fronts of the extreme positions with simultaneous reconstruction. These interference lines represent lines of equal amplitude on the compressor impeller, i.e. deformation contours. The white areas represent nodal zones with zero amplitude.

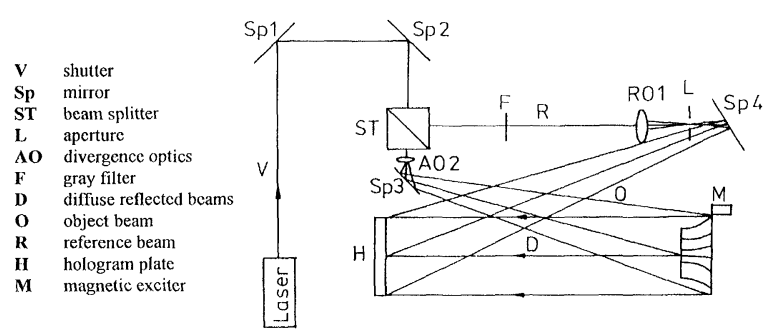

FIGURE 4 Experimental set-up for the optical investigation of the impeller by means of holographic interferometry.
A qualitative evaluation may therefore be easily carried out as the interference lines provide an exact picture of the vibration behavior. As the amplitudes also depend on the excitation intensity, which is neither accounted for in the FE method (see Part II) nor in the time-average method, it is only possible to compare computations and measurements in qualitative terms.

In order to experimentally investigate coupled vibration behavior, the impeller with its shaft was assembled on a small test stand and excited by a sinusoidal generator via a shaker. Figure 5 shows the test set-up. The shaker consists of an electrodynamic excitation unit which introduces sinusoidal forces into the outer part of the impeller disc via a reciprocating rod directly between two blades. With the aid of a sinusoidal generator which controls the shaker via an amplifier, it was possible to vary the frequency from 0 to $7000 \mathrm{~Hz}$. As only two channels were available, one strain gage was mounted on a normal blade and the other on the inside of the impeller disc in the outlet region between two blades. The splitter blade was not included in the tests. The signals from the strain gages were analyzed with the aid of a frequency analyzer, thereby enabling the coupled natural frequencies to be determined.

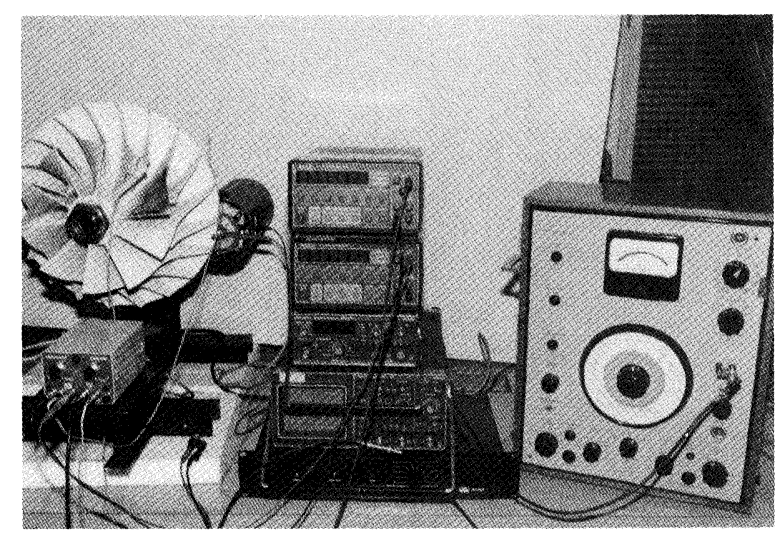

FIGURE 5 Small test stand for investigating the vibration behavior of radial impellers at rest. Excitation by means of a shaker. 


\section{EXPERIMENTAL RESULTS}

\section{Measured Frequencies}

A comparison between the measurements and the FE computations is given in Figs. 6 and 7, whereby Fig. 6 shows the strain gage measurements on a blade while Fig. 7 shows the measurements on the impeller disc. A in each figure indicates the results of the FE computations for the half-impeller with blade thickness variation whereas $B$ indicates the measurements.

A difference between the measurements and computations is immediately apparent. Whereas the experiments yielded both the coupled natural frequencies as well as the corresponding amplitudes, the computations were unable to provide any information concerning the amplitudes as these are highly dependent on the excitation forces. In the case of measurements, the amplifier voltage of the shaker was held constant over the entire frequency range. Bearing in mind that the strain gage on the normal blade is unable to detect vibrations of the splitter blade, relatively good agreement is obtained between the computed and measured coupled natural frequencies. Large phase shifts are apparent in Fig. 6 only for the coupled natural frequency ranges

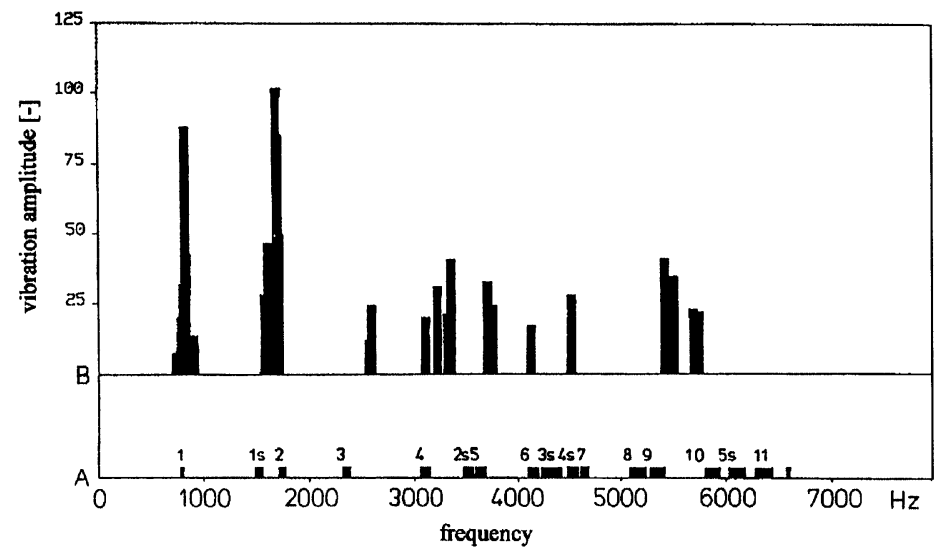

FIGURE 6 Coupled vibration frequencies of the 28-bladed $90^{\circ}$-impeller. Comparison between the FE computational results (A) for the part model with 14 blades and measurements (B) for the impeller at rest with a strain gage on the normal blade.

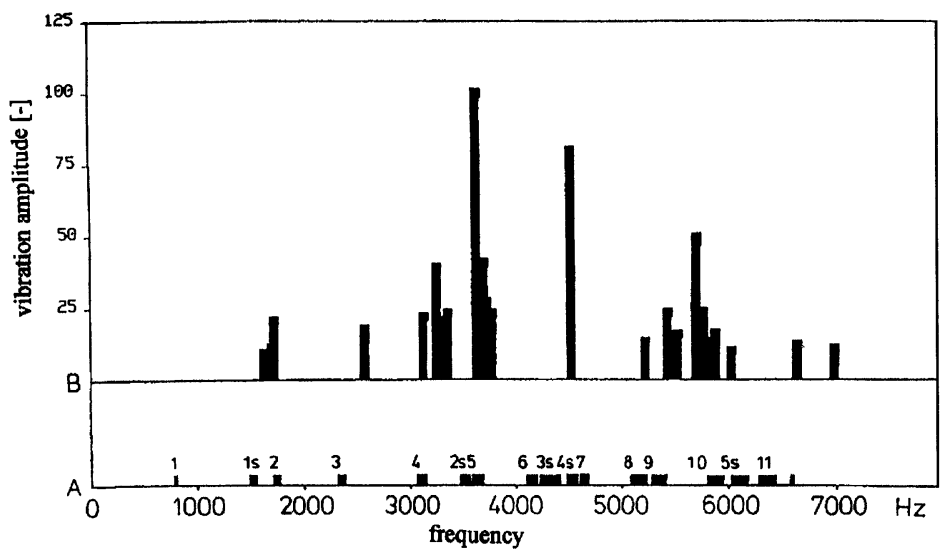

FIGURE 7 Coupled vibration frequencies of the 28-bladed $90^{\circ}$-impeller. Comparison between the FE computational results (A) for the part model with 14 blades and measurements (B) for the impeller at rest with a strain gage on the impeller disc. 


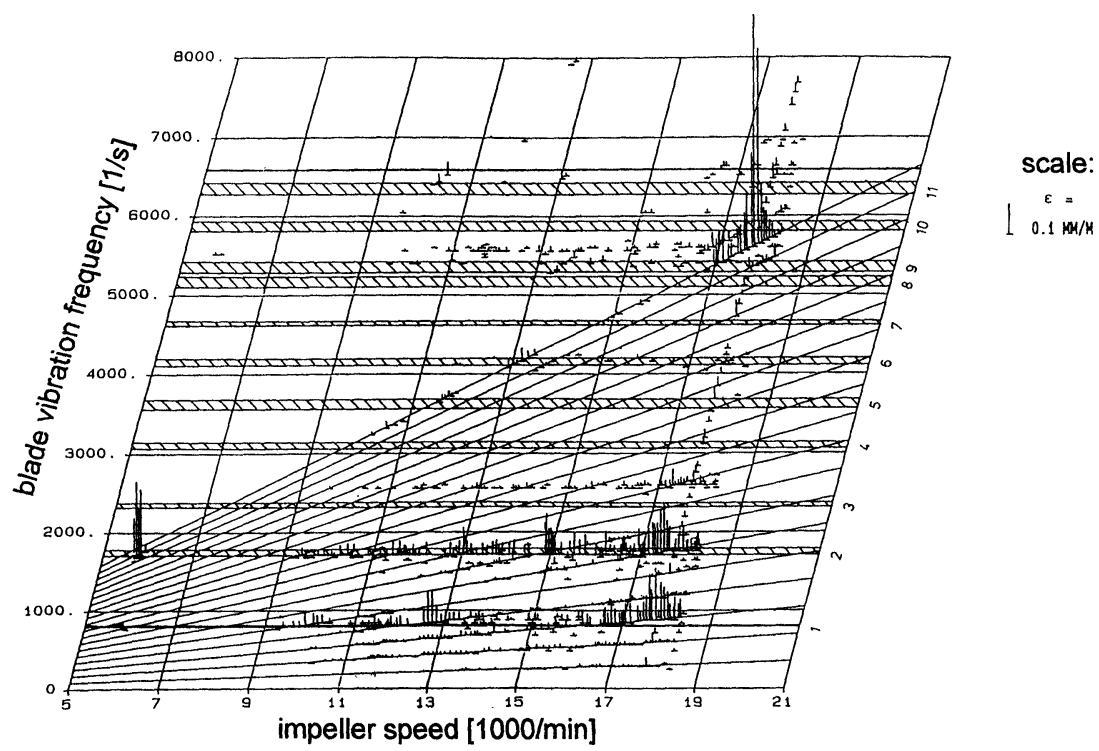

FIGURE 8 Blade vibrations of the 28-bladed $90^{\circ}$-impeller depicted in the Campbell diagram. Results of measurements with a strain gage on the normal blade as well as computed coupled vibration natural frequencies corresponding to the normal blades.

3, 7 and 10. The 8 th natural frequency is not registered by the measurements.

The representation in Fig. 7 also indicates larger phase shifts at the natural frequencies 3 and 7 whereas the remaining normal blade natural frequency bands as well as several splitter blade natural frequency bands are satisfactorily reproduced. The fundamental frequency as well as the 6th natural frequency of the normal blade is not detected by this strain gage which is located on the impeller disc. It is noticeable in the case of this measurement that the middle and higher coupled natural frequencies in particular are well reproduced whereas a better reproduction of the lower frequencies is given by the strain gage on the normal blade.

In addition to the tests with the impeller at rest, extensive blade vibration measurements were also carried out on the rotating impeller. In this case the signals from the semiconductor strain gages applied to the blades and the disc were transmitted from the rotating impeller to a fixed receiver by means of the above-described 8-channel telemetry unit and recorded on magnetic tape. The vibration signals were subsequently analyzed with the aid of a frequency analyzer.
Figure 8 shows the results of the analysis of the vibration signal for a normal blade during a test run presented in a Campbell diagram. The vibration loading with varying frequency is plotted in the figure as a function of the rotor speed. This illustrates the frequency-dependent material loading of the normal blade at the position of the applied strain gage for the overall speed range relevant to the operation of the compressor. As the strain gage only measures the material loading at a single location (in this case the stress maximum of the first mode shape), precise information concerning the loading of the remaining blade regions cannot be deduced from this figure.

Moreover, the Campbell diagram presented is only valid for one throttle position. For a different throttle position, i.e. in the part-load region, other excitation forces occur in part which give rise to a different amplitude distribution. Besides the measured results, the computed coupled vibration natural frequencies of the $90^{\circ}$-radial impeller model with 14 blades are also plotted in the diagram. These are based on the FE results with thickness variation. For the purpose of clarity only the frequency bands corresponding to the normal 


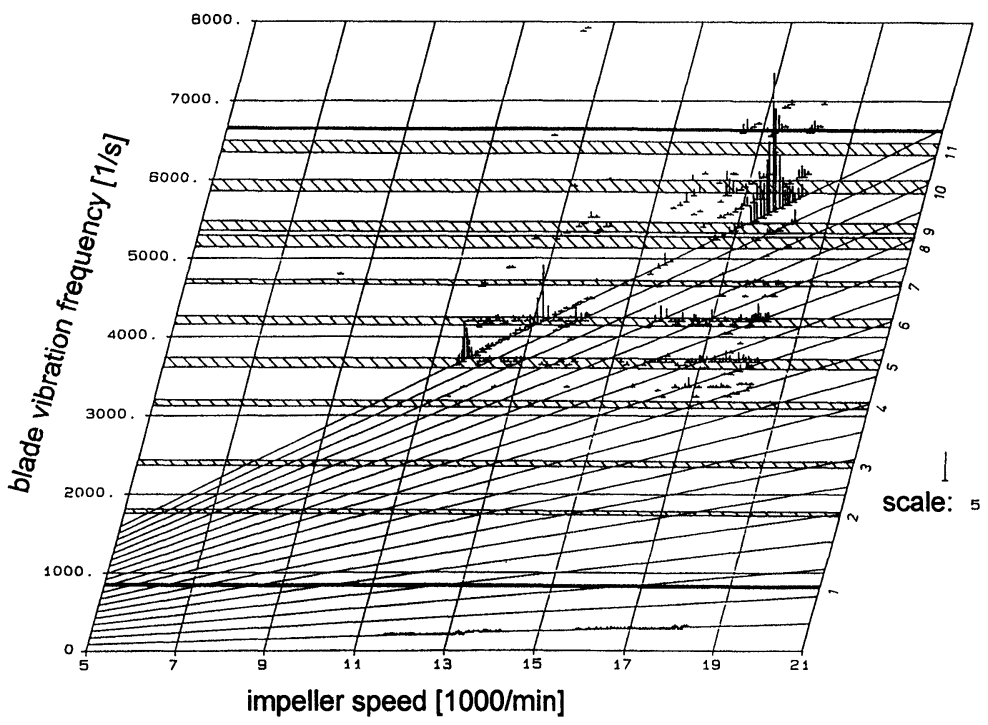

FIGURE 9 Blade vibrations of the 28-bladed $90^{\circ}$-impeller depicted in the Campbell diagram. Results of measurements with a strain gage on the impeller disc as well as computed coupled vibartion natural frequencies corresponding to the normal blades.

blades were considered. These are represented as horizontal lines or shaded areas in the figures. Whereas good agreement was obtained between measurements and computations in the case of the first two natural frequencies, a large deviation was observed in the case of the third natural frequency. The same result was also apparent in the measurements with the impeller at rest. The small amplitudes measured in the case of the natural frequency bands 4, 5, 6 and 7 do not permit an exact comparison. As far as is recognizable the 5th, 6th and 7th natural frequencies are reproduced well by the computations whereas the 4th natural frequency is shifted downwards slightly. The most striking feature is the high material loading measured in the range of $5400-5800 \mathrm{~Hz}$ at a speed of $18,000 \mathrm{rpm}$.

The Campbell diagram presented in Fig. 9 shows the measured and computed results for a strain gage applied to the impeller disc in the outlet region between two blades. As already noted in the case of the stationary measurements, the lower four natural frequencies of the normal blade are not registered by this strain gage whereas the middle and higher natural frequencies, whose mode shapes indicate increased vibration intensity at the impeller outlet, are well registered. In overall terms, the two Campbell diagrams together provide a relatively comprehensive overview of the actual vibration behavior of the impeller.

\section{Measured Mode Shapes}

The computed mode shapes for the half-impeller model with 14 blades were taken as a basis for comparison with the holographic mode shapes. The holographic interferogram illustrated in Fig. 10 was recorded at $790 \mathrm{~Hz}$ and shows the 28-bladed $90^{\circ}$ impeller, whose 14 normal blades vibrate in their fundamental mode shape.

The interference fringe pattern indicates that the largest amplitudes occur at the blade tips at the impeller inlet. The blades with the more dense line pattern vibrate at a larger amplitude than the blades with wide interference lines. The outlet region and the impeller disc do not contribute towards the vibration mode shape. Computations for the coupled system, as shown in Fig. 11, indicate normal blade vibrations in the fundamental mode shape. As the blades partly overlap, the plot of the 


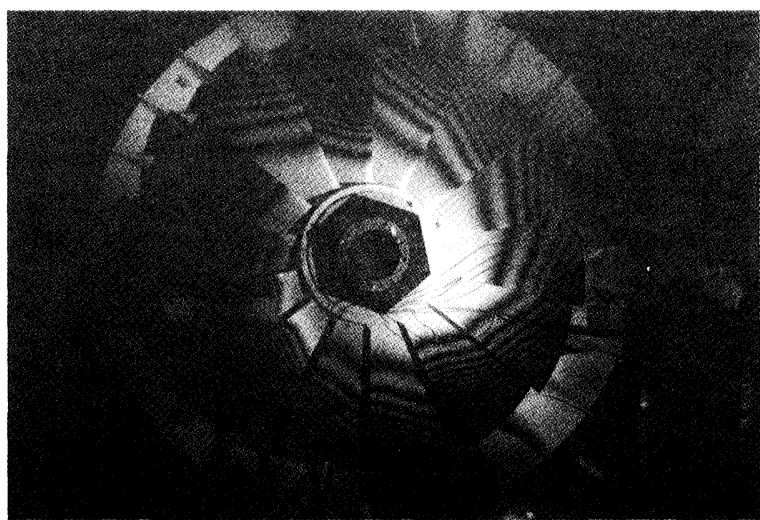

FIGURE 10 Holographic interferogram of the $90^{\circ}$-impeller with 28 blades at a frequency of $790 \mathrm{~Hz}$.

half-impeller is very unclear. For this reason, only the leading edges of the blades are plotted in the lower part of the figure. This representation clearly shows that the normal blades vibrate in pairs in the opposite sense in their fundamental mode shape whereas the splitter blades remain at rest. It is also found that the computed mode shapes for individual blades exhibit different vibration amplitudes.

Of special interest are the mode shapes of the impeller with a significant contribution from the outer portion of the impeller disc, i.e. for modes with high coupling between blades and disc. Such a mode shape is illustrated by the interferograms shown in Fig. 12, which depict the impeller from the front and back sides at a frequency of about $3620 \mathrm{~Hz}$. Apart from the blade vibrations strong vibrations are also evident in the outlet region between the blades, although not every interblade region is affected.

Regarding the aforementioned measurements on the running impeller (see Campbell diagram in Fig. 8), large vibration amplitudes of the 9th and 10th normal blade mode shapes were registered at 5400 and $5700 \mathrm{~Hz}$. Both vibration modes were excited by coupling action of the 19-blade diffuser in the outlet region and exhibit high stresses at the position of the applied strain gages at about half the blade height at the inlet.

The hologram shown in Fig. 13, which was recorded at $5400 \mathrm{~Hz}$, reveals large vibrations of the
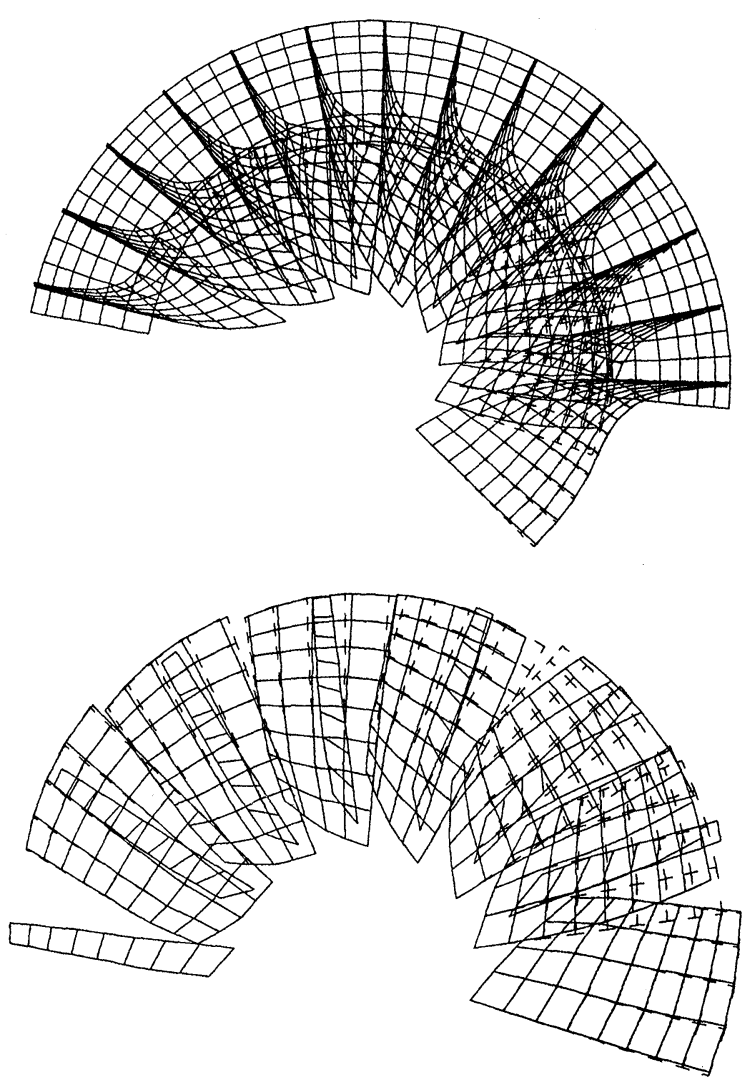

FIGURE 11 Computed 1st mode shape of the part structure of the $90^{\circ}$-radial impeller with 14 blades at $780 \mathrm{~Hz}$.

inlet region. Antinodes are also apparent along the outer region of the impeller disc between the blades, although the amplitudes of the latter are very small.

The computed mode shape at $5235 \mathrm{~Hz}$ is shown in Fig. 14. The leading edge of the blade exhibits the same vibration mode as the hologram and the blades also vibrate with very different amplitudes. An absence of vibration was apparent in the case of several blades. A view of the impeller disc also reveals large amplitude differences in the vibrations between the blades.

The interferograms recorded at $5680 \mathrm{~Hz}$ are shown in Fig. 15. In this frequency range the Campbell diagram also reveals large material loading at the inlet due to vibration excitation via the diffuser vanes. The recordings also indicate large vibrations at the inlet. The vibration pattern in 

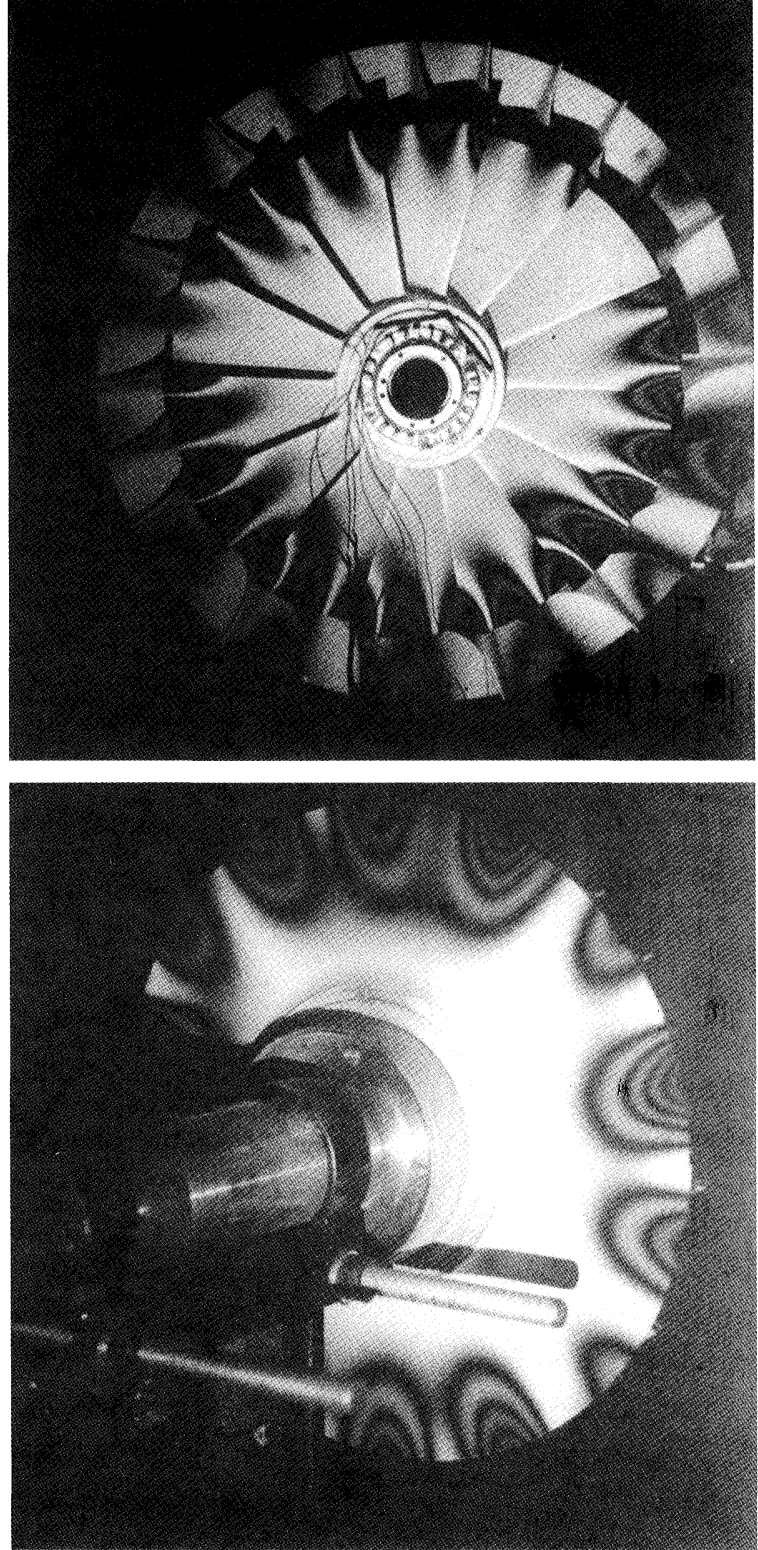

FIGURE 12 Holographic interferogram of the $90^{\circ}$-impeller with 28 blades. Recording at $3620 \mathrm{~Hz}$ from the front (above) and the back (below).

this region is extremely complex. The vibration amplitudes again vary from blade-to-blade and the vibration modes of the individual blades are nonuniform. This is reflected in different mode line curves. Some blades vibrate in the 9 th mode shape whereas others vibrate in the 10th mode shape.
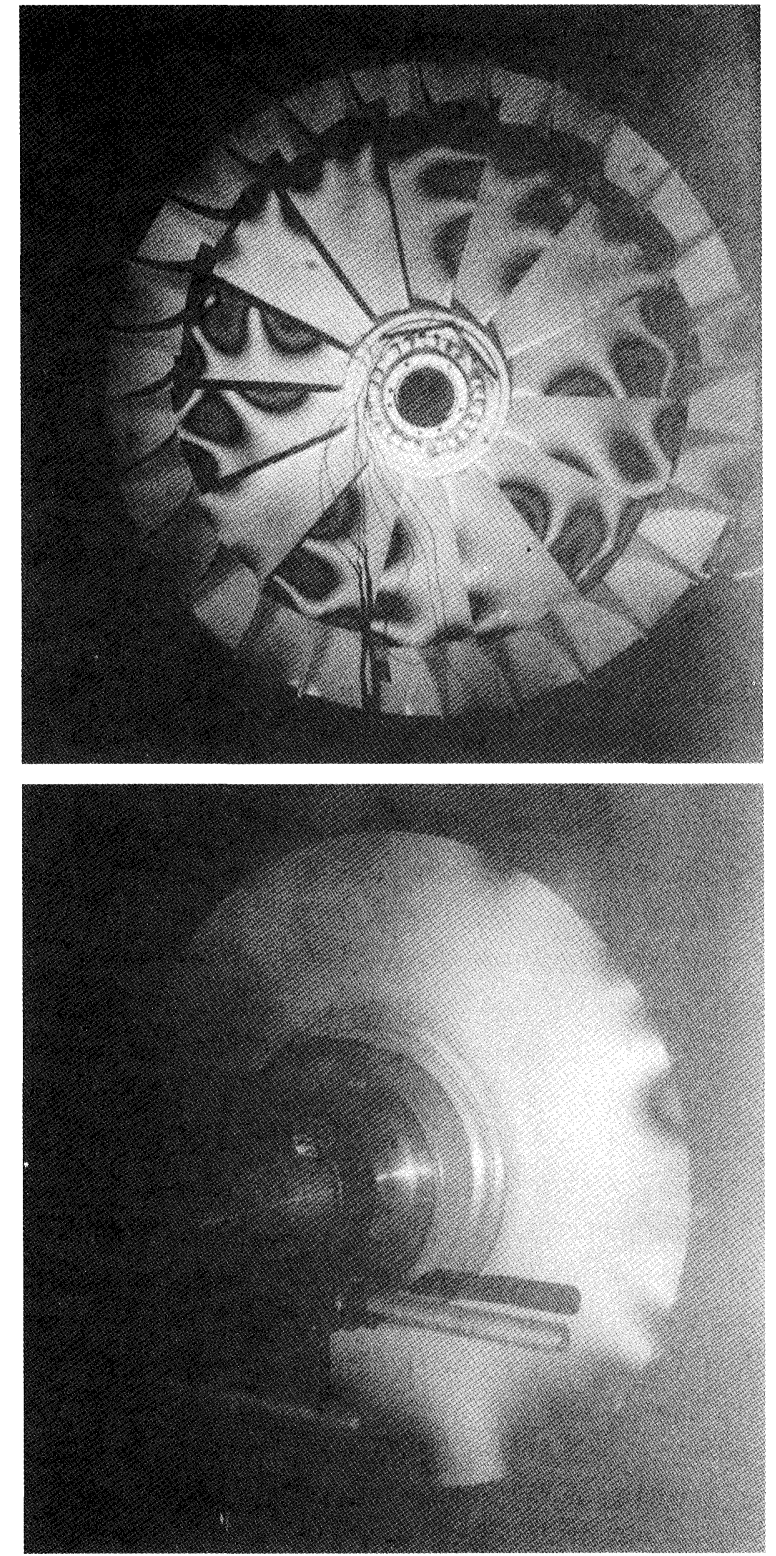

FIGURE 13 Holographic interferogram of the $90^{\circ}$-impeller with 28 blades. Recording at $5400 \mathrm{~Hz}$ from the front (above) and the back (below).

Antinodes observed on the impeller disc are partly restricted to the interblade region and also partly overlap.

The computed mode shape at $5749 \mathrm{~Hz}$ presented in Fig. 16 also reveals large vibration amplitudes of the blades at the inlet region as well as antinodes 


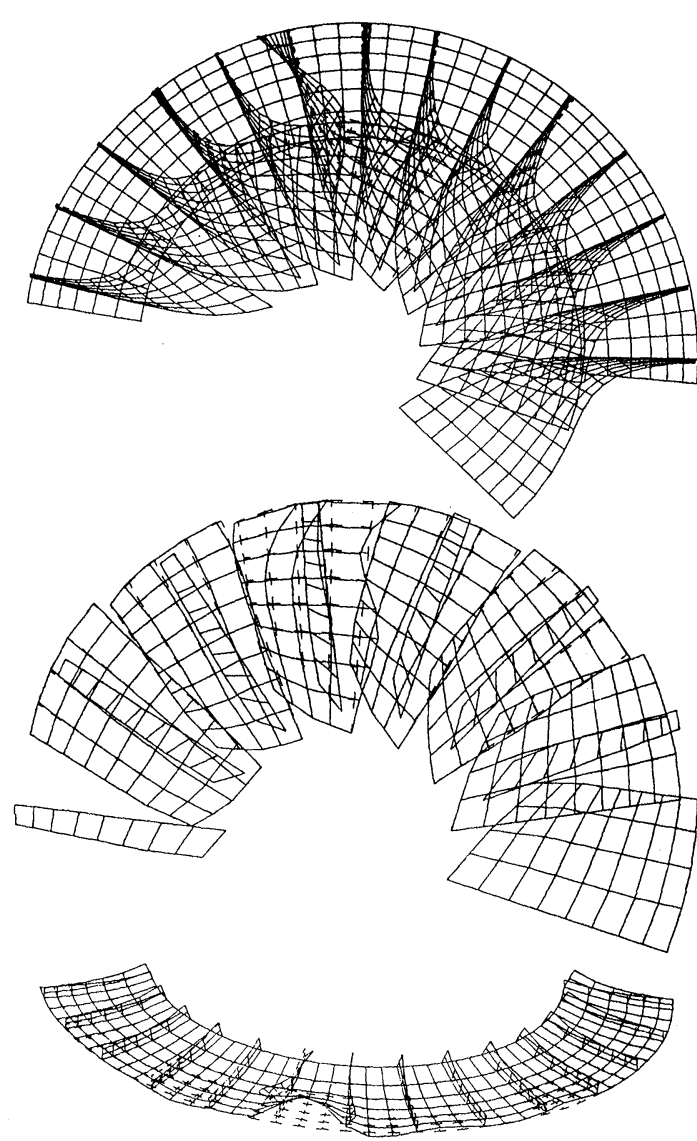

FIGURE 14 Computed 86th mode shape of the part structure of the $90^{\circ}$-radial impeller with 14 blades at $5235 \mathrm{~Hz}$.

on the impeller disc which extend over several interblade regions. The vibration behavior in the blade inlet region is highly complex and is again characterized by different amplitudes. For the two normal blades on the left-hand boundary, which exhibit only slight vibrations at the inlet, the unique specification of a mode shape is not possible. The remaining normal blades, however, vibrate in their 10th mode shape.

At these high mode shapes the FE structure attains the limits of its accuracy. In principle, a finer discretization of the blade computational mesh as well as the impeller disc structure would be necessary to obtain more exact results. This cannot always be realized, however, due to limited computing capacity and cost considerations.
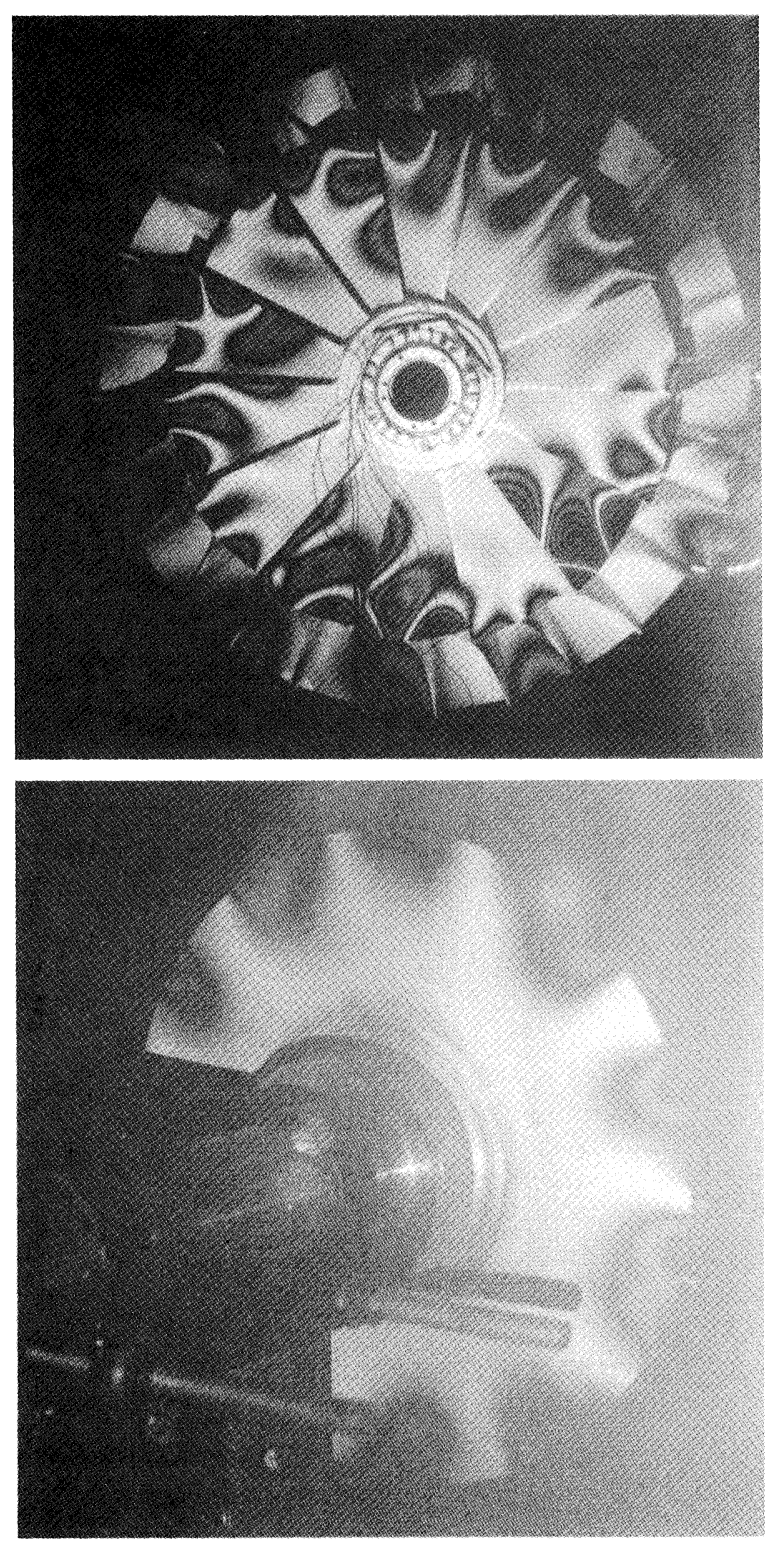

FIGURE 15 Holographic interferogram of the $90^{\circ}$-impeller with 28 blades. Recording at $5680 \mathrm{~Hz}$ from the front (above) and the back (below).

\section{CONCLUSIONS}

The experimental investigations, involving the use of applied strain gages and data telemetry as well as holographic interferometry, have made it possible to determine coupled natural frequencies and coupled mode shapes over a wide frequency range, 


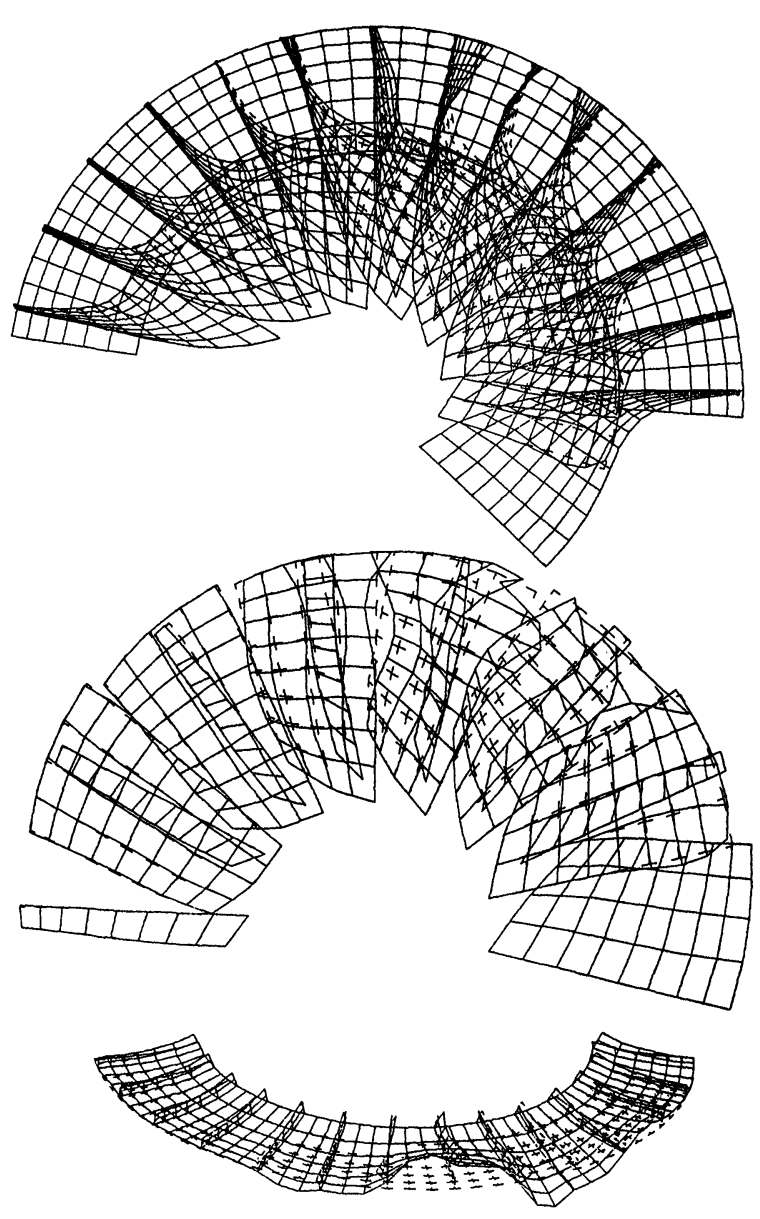

FIGURE 16 Computed 93rd mode shape of the part structure of the $90^{\circ}$-radial impeller with 14 blades at $5749 \mathrm{~Hz}$.

thereby providing fundamental knowledge concerning the extremely complex vibration behavior of radial impeller structures in practice.

On the basis of the experimental results, it was possible to validate the applicability of the FE method to problems of this nature. Despite the reduction of the impeller model to one half and the somewhat coarse discretization of the models for investigating higher mode shapes, the FE computations for the $90^{\circ}$-impeller were found to agree closely with the experimental results with regard to frequencies as well as mode shapes in most cases. As dangerous coupled blade vibrations are more predominant in the middle and higher frequency ranges, finer discretization of the models should be aimed at within the framework of increased computer capacities in order to arrive at more exact prognoses of the particular parts of the impeller structure at risk. Despite this shortcoming, the FE model of the half-impeller used in the present investigation was still capable of yielding relatively good results.

\section{Acknowledgments}

The authors gratefully acknowledge the financial support of the German Research Association(DFG) throughout this research project. They would also like to thank Dr. Haupt and Dr. Jin for their cooperation as well as Mr. Tanneberg for running the tests and Mr. Wichmann for conducting the measurements. The authors are also indebted to Dr. Ian Westwood (Burgwedel, Germany) for his meticulous translation of this paper.

\section{References}

Hasemann, H., Oberröhrmann, A., Hagelstein, D. and Rautenberg, M. (1995) Investigation of the solidity and the blade vibration behaviour of radial compressor impellers due to a significant reduction of the hyperbolic undercut in the flankmilling process, Yokohama International Gas Turbine Congress, Yokohama, Japan, Oct 22-27.

Haupt, U. and Rautenberg, M. (1978) Zur Untersuchung von Schaufelschwingungen an Laufrädern hochbelasteter Radialverdichter mittels Datentelemetrie, MTZ Motor-technische Zeitschrift 39, Bd. 4, S. 177-183.

Haupt, U. and Rautenberg, M. (1982a) Investigation of blade vibration of radial impellers by means of telemetry and holographic interferometry, ASME-Paper No. 82-GT-34, Int. Gas Turbine Conference of the ASME, London, England, April 18-22. Transactions of the ASME, Journal of Engineering for Power, Vol. 104, No. 4, October 1982, pp. 838/843.

Haupt, U. und Rautenberg, M. (1982b) RadialverdichterSchaufelschwingungen, Forschungsvereinigung Verbrennungskraftmaschinen e.V., Frankfurt, FVV- Forschungs-bericht, Heft 315.

Haupt, U. und Rautenberg, M. (1982c) Untersuchung von Schaufelschwingungen an hochbelasteten Radialverdichterlaufrädern fortschrittlicher Technologie, Forschungsvereinigung Verbrennungskraftmaschinen e.V., Frankfurt, FVV- Forschungsbericht, Heft R 425.

Haupt, U., Kreitlow, H. and Rautenberg, M. (1982) Blade vibration measurements by means of telemetry and holographic interferometry on a radial impeller with thin blades, Paper No. V-55, Fourth International Conference for Mechanical Power Engineering, Cairo, Egypt.

Haupt, U. (1984) Untersuchung des Schaufelschwingungsverhaltens hochbelasteter Radialverdichterlaufräder, Dissertation, Universität Hannover, 1984. 
Haupt, U., Rautenberg, M. and Diefenthäler, K. (1984) Beschleunigungsfeste 8-Kanal-Telemetrieanlage für Schaufelschwingungsmessungen am Radialverdichter, Europäische Telemetrie-Konferenz, ETC '84, Böblingen, Mai 1984. Acceleration Proof 8-Channel-Telemetry-System for Blade Vibration Measurements on a Centrifugal Compressor. European Telemetry Conference, 21-24. Mai 84, Böblingen, FRG.
Haupt, U., Bammert, K. and Rautenberg, M. (1985) Blade vibration on centrifugal compressors - Fundamental considerations and initial measurements, ASME-Paper No. 85-GT92, Int. Gas Turbine Conference of the ASME, Houston, Texas, USA, March 18-21, 1985. 


\section{ait \\ ENERGY MATERIALS}

M A N E Y publishing

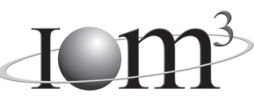

\section{Materials Science \& Engineering for Energy Systems}

Maney Publishing on behalf of the Institute of Materials, Minerals and Mining

The Institute of Materials, Minerals \& Mining

Economic and environmental factors are creating ever greater pressures for the efficient generation, transmission and use of energy. Materials developments are crucial to progress in all these areas: to innovation in design; to extending lifetime and maintenance intervals; and to successful operation in more demanding environments. Drawing together the broad community with interests in these areas, Energy Materials addresses materials needs in future energy generation, transmission, utilisation, conservation and storage. The journal covers thermal generation and gas turbines; renewable power (wind, wave, tidal, hydro, solar and geothermal); fuel cells (low and high temperature); materials issues relevant to biomass and biotechnology; nuclear power generation (fission and fusion); hydrogen generation and storage in the context of the 'hydrogen economy'; and the transmission and storage of the energy produced.

As well as publishing high-quality peer-reviewed research, Energy Materials promotes discussion of issues common to all sectors, through commissioned reviews and commentaries. The journal includes coverage of energy economics and policy, and broader social issues, since the political and legislative context influence research and investment decisions.

\section{CALL FOR PAPERS}

Contributions to the journal should be submitted online at http://ema.edmgr.com

To view the Notes for Contributors please visit: www.maney.co.uk/journals/notes/ema

Upon publication in 2006, this journal will be available via the Ingenta Connect journals service. To view free sample content online visit: www.ingentaconnect.com/content/maney

For further information please contact:

Maney Publishing UK

Tel: +44 (0)113 2497481 Fax: +44 (0)1132486983 Email: subscriptions@maney.co.uk

or

Maney Publishing North America

Tel (toll free): 8662975154 Fax: 6173546875 Email: maney@maneyusa.com

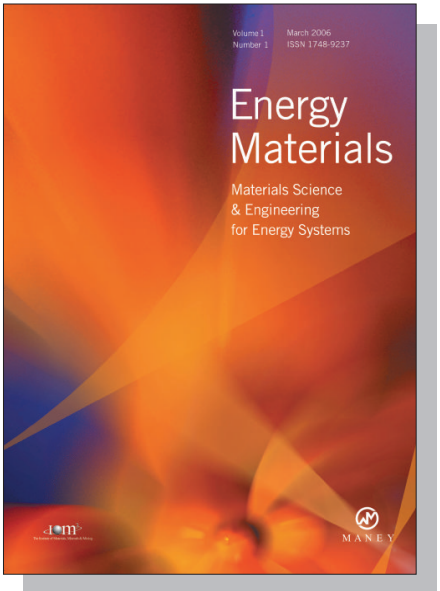

EDITORS

Dr Fujio Abe

NIMS, Japan

Dr John Hald, IPL-MPT, Technical University of Denmark, Denmark

Dr R Viswanathan, EPRI, USA

\section{SUBSCRIPTION INFORMATION}

Volume 1 (2006), 4 issues per year

Print ISSN: 1748-9237 Online ISSN: 1748-9245

Individual rate: $£ 76.00 / U S \$ 141.00$

Institutional rate: $£ 235.00 /$ US $\$ 435.00$

Online-only institutional rate: $£ 199.00 / U S \$ 367.00$

For special $\mathrm{IOM}^{3}$ member rates please email

subscriptions@maney.co.uk

\section{For further information or to subscribe online please visit www.maney.co.uk}



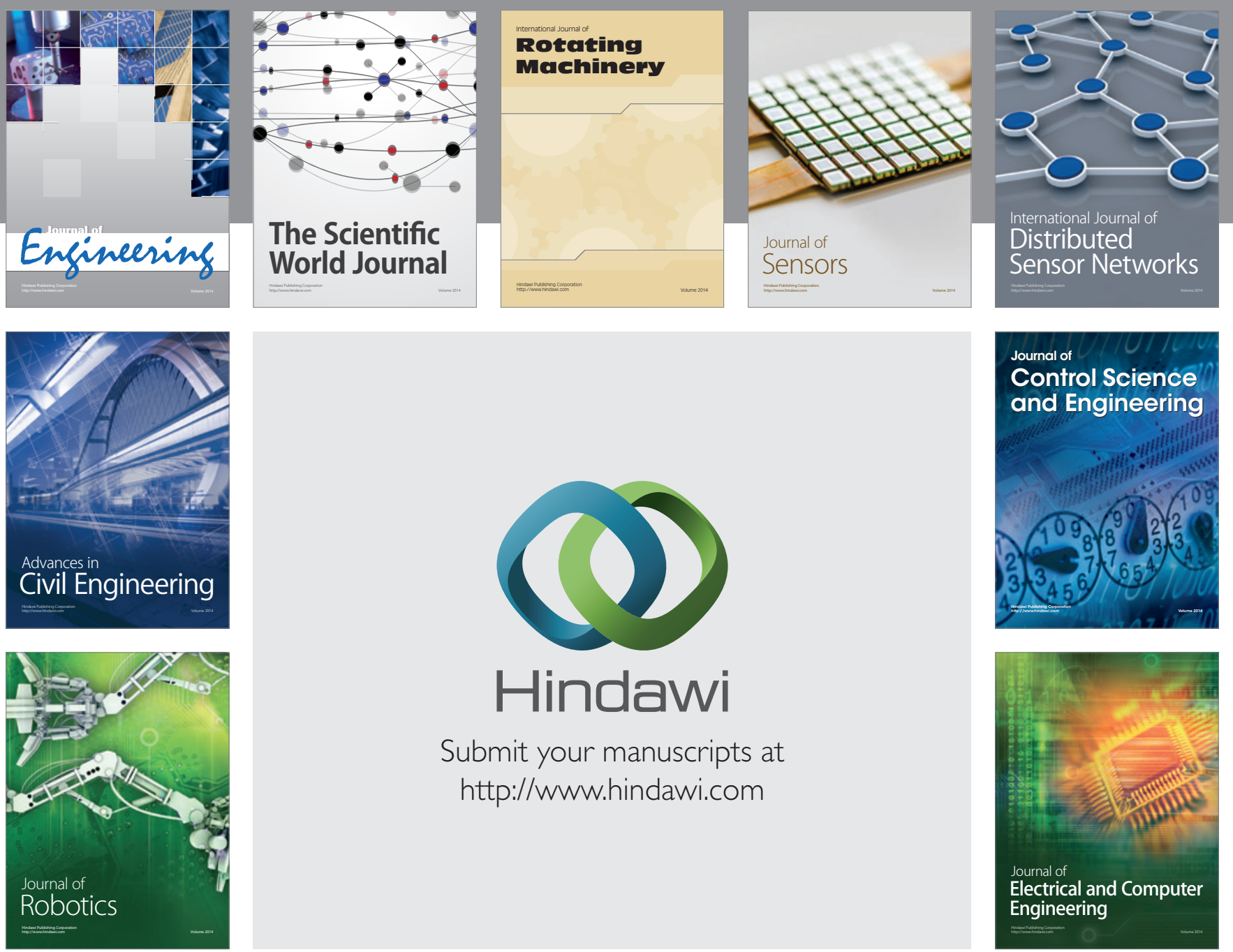

Submit your manuscripts at

http://www.hindawi.com
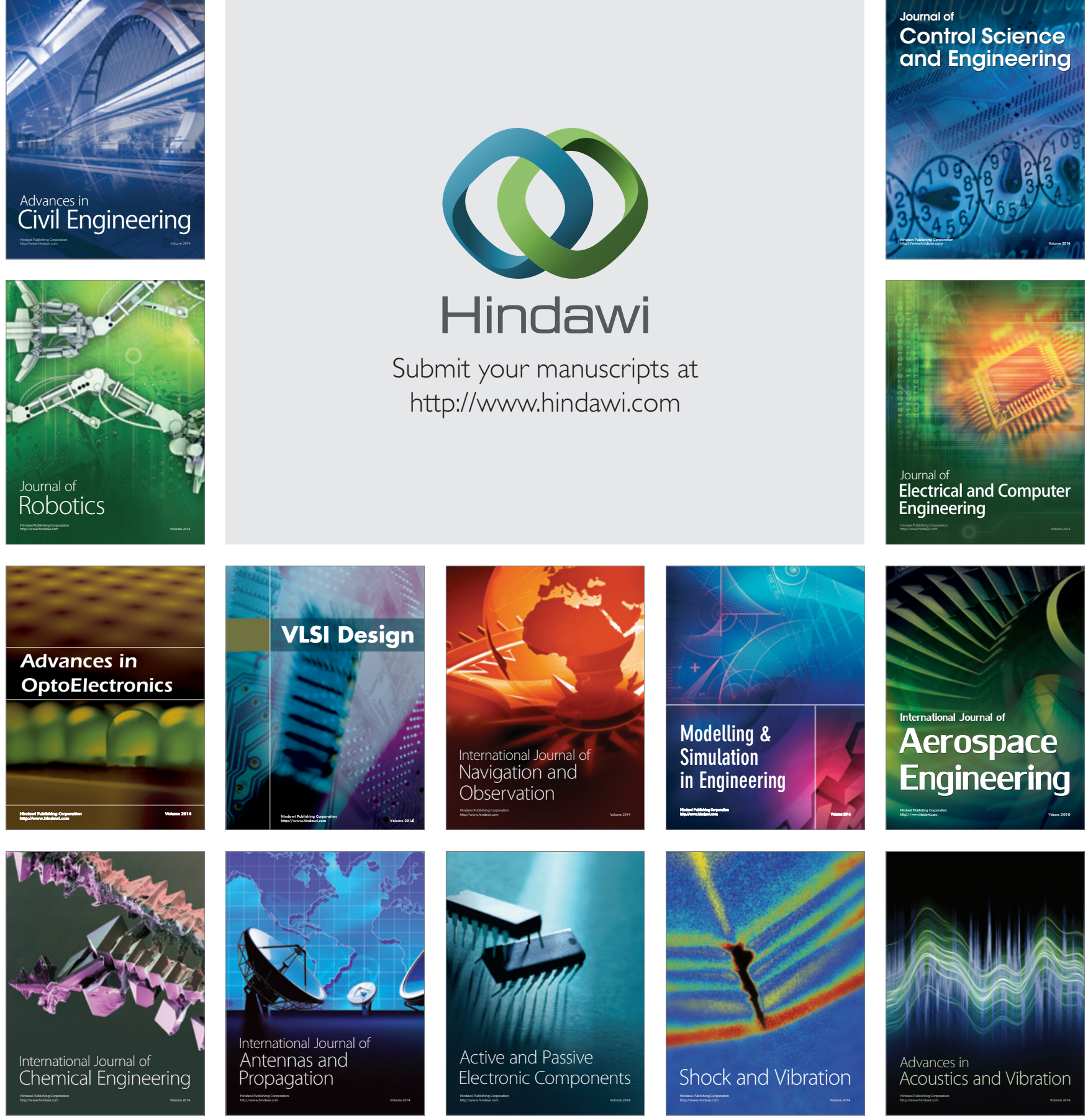